\title{
Withdrawing critical care from patients in a triage situation
}

\author{
Joseph Tham ${ }^{1}$ (D) Louis Melahn ${ }^{1} \cdot$ Michael Baggot $^{1}$ \\ Accepted: 19 December 2020 / Published online: 4 January 2021 \\ (c) The Author(s), under exclusive licence to Springer Nature B.V. part of Springer Nature 2021
}

\begin{abstract}
The advent of COVID-19 has been the occasion for a renewed interest in the principles governing triage when the number of critically ill patients exceeds the healthcare infrastructure's capacity in a given location. Some scholars advocate that it would be morally acceptable in a crisis to withdraw resources like life support and ICU beds from one patient in favor of another, if, in the judgment of medical personnel, the other patient has a significantly better prognosis. The paper examines the arguments for and against this approach from the point of view of natural law theory, especially using the principle of double effect. We conclude that it is inadmissible to withdraw life-saving medical interventions from patients who are still benefiting from them, on the sole grounds that other patients might benefit more. Those who are currently using such technology should only interrupt their treatment if, in the judgment of medical personnel and, if possible, taking into account the wishes and needs of the patient and his family, the treatment is deemed futile, burdensome, or disproportionate.
\end{abstract}

The advent of COVID-19, caused by a deadly novel coronavirus, has been the occasion for a renewed interest in the principles governing triage when the number of critically ill patients exceeds the healthcare infrastructure's capacity in a given place. In a few locations, such as Bergamo, Italy (Horowitz 2020), and Madrid, Spain (Cadenas and Valdés 2020; Lüdke 2020), it has been necessary to do triage due to an uncontrolled local surge in the number of severe cases of the disease. Fortunately, the United States has avoided such situations (Centers for Disease Control and Prevention 2020; Feuer and McKinley 2020; NYC Health 2020). Nevertheless, there is still the possibility that such cases could arise in the future, either in places that have not yet had appreciable exposure to COVID-19 or else should there be a resurgence of the virus once mitigation measures designed to contain its spread are relaxed (McNeil 2020).

Of particular interest is how we should allocate scarce life-saving resources such as ventilators. Emanuel et al. in their article for the New England Journal of Medicine

Joseph Tham

jtham@legionaries.org

Louis Melahn

lmelahn@legionaries.org

Michael Baggot

mbaggot@legionaries.org

1 School of Bioethics, Pontificio Ateneo Regina Apostolorum, Via degli Aldobrandeschi 190, 00163 Rome, Italy
$(N E J M)$ summarize the issue that this paper will deal with as follows:

Undoubtedly, withdrawing ventilators or ICU support from patients who arrived earlier to save those with better prognosis will be extremely psychologically traumatic for clinicians-and some clinicians might refuse to do so. However, many guidelines agree that the decision to withdraw a scarce resource to save others is not an act of killing and does not require the patient's consent. We agree with these guidelines that it is the ethical thing to do. Initially, allocating beds and ventilators according to the value of maximizing benefits could help reduce the need for withdrawal (Emanuel et al. 2020, pp. 4-5).

In other words, according to the recommendation Emanuel et al., it would be morally acceptable in a crisis to withdraw resources like life support and ICU beds from one patient in favor of another, if, in the judgment of medical personnel, the other patient has a significantly better prognosis. Indeed, such a course of action would be preferable. Similarly, Truog, Mitchell, and Daley suggest that in a crisis, doctors may withdraw ventilators from patients currently benefiting from the treatment for the sake of patients more likely to benefit even though the reallocation "is not being done at the request of the patient or surrogate, nor can it be claimed that the treatment is futile" (Truog et al. 2020, p. 2). 
This recommendation has also been echoed in Catholic circles. For example, Boston College theology professor Daniel Daly has taken a similar position in his guidelines for rationing treatment, published in the Catholic Health Association's journal Health Progress, albeit without going so far as to assert that it is ethical to withdraw life-saving treatment even without obtaining the consent of the patient:

Medical facilities can withdraw treatment from a patient to reallocate a limited resource to a different patient who is expected to realize a more significant medical benefit from the treatment. This applies even if the cessation of the treatment is expected to result in the death of the patient. In such an instance, Catholic teaching holds that medical facilities that withdraw life-sustaining treatment have allowed the patient to die of her underlying condition; the facility has not killed or euthanized the patient (Daly 2020).

On the other hand, this view is challenged by other authors. The National Catholic Bioethics Center (NCBC) believes that critical treatment should never be withdrawn without first establishing that such treatment is burdensome or futile, and without making some attempt to offer the patient or his surrogate the possibility of discontinuing treatment voluntarily:

Various protocols state that physicians can withdraw critical care from patients who they believe have no chance at survival regardless of the patient's or the surrogate's wishes. While some circumstances might warrant a physician's order to cease critical care interventions, this cessation should only happen after appropriate communication with the patient or surrogate about the triage situation and the medical recommendation. This communication should include the burdens and clinical expectation of no recovery and offer the patient or surrogate the opportunity to voluntarily discontinue the intervention. After appropriate communication and opportunity for voluntary discontinuation, and in light of a triage situation in which others' lives are at stake, physicians should be able to override unreasonable patient or surrogate demands to continue intensive care support (NCBC Ethicists 2020).

Similarly, the guidelines of the Anahuac University Mexico have come out strongly against using double effect as a justification for withdrawing critical care (Anahuac University Mexico 2020, p. 10).

This paper will assess whether the recommendation to withdraw scarce life-saving treatment in favor of patients with better foreseen health outcomes is in accord with a natural-law based ethics, especially using double-effect reasoning. To analyze this problem, let us state a couple of hypothetical scenarios in which we could apply the triage principles.

Scenario 1: Four patients arrive at the emergency room at roughly the same time. We will call them A, B, C, and D. After assessment by medical personnel, all four patients would need to be placed on a ventilator soon-otherwise, they will die. Unfortunately, all the ventilators are occupied save one, and it will be a week before any new ones come online. According to the assessment, all the patients would benefit from a ventilator-that is, if four ventilators were available, the hospital would recommend intubating all four patients, as all have a reasonable chance of recovering. Patient $\mathrm{A}$ is the one likeliest to survive and recover well, followed by patient $\mathrm{B}$, and so on. The question then arises: given those unfortunate circumstances outside the hospital's control, would it be acceptable for the hospital to opt to intubate patient $\mathrm{A}$, and give only palliative care to patients $\mathrm{B}, \mathrm{C}$, and $\mathrm{D}$ ?

The article from Emmanuel et al. and Daly's guidelines agree that the answer would be yes. Emmanuel et al. state,

Operationalizing the value of maximizing benefits means that people who are sick but could recover are given priority over those who are unlikely to recover even if treated and those who are likely to recover without treatment (Emanuel et al. 2020, p. 4).

and Daly's guidelines affirm,

Scarce resources should be distributed according to the expected medical benefit to the patient. Patients who are most likely to benefit medically from an intervention should be prioritized for that treatment (Daly 2020).

Similarly, the other sources reviewed would have no objection to the allocating resources in this way (Anahuac University Mexico 2020, pp. 8-9; NCBC Ethicists 2020, p. 1; Truog et al. 2020, p. 1; Vergano et al. 2020, p. 2; White et al. 2020, p. 1; White and Lo 2020, p. 1773). We agree with these authors that merely allocating the resources available to the best of our ability cannot be considered an act of direct killing-which we will define as intentionally or voluntarily bringing about a person's death-even though we foresee that some patients would not survive without intubation. In general, no actions or omissions leading unintentionally to the deaths of patients $\mathrm{B}, \mathrm{C}$, and $\mathrm{D}$ can be classified as a direct killing. The medical staff that intubates patient A simply recognizes that, despite their best efforts, three of the four patients cannot be saved. Therefore, the medical personnel should assess prudently who will receive the treatment, a task assisted by criteria such as SOFA (Di Camillo 2020; Snell 2020). As the Latin maxim says, ad impossibilia nemo tenetur: no one is ever obligated to do the impossible. 
To obtain a better understanding of why it is morally acceptable to withhold access to a ventilator (giving palliative care instead) in this scenario, it can be useful to analyze it according to the principle of double effect, that is, the principle that helps us discern whether the bad consequences of doing triage (in which patients $\mathrm{B}, \mathrm{C}$, and $\mathrm{D}$ will be deprived life-saving treatment) are merely unwanted but tolerated side effects of attempting to do something good.

Before entering into the principle as such, a few observations are in order regarding what exactly we mean by intent and the definition of direct killing. As Thomas Aquinas notes in the article in the Summa Theologiae that gives double effect its name, when an act has more than one consequence, some of these can be "in the intention" of the agent, whereas others might be "beside the intention": "Nothing hinders one act from having two effects, only one of which is intended (in intentione), while the other is beside the intention (praeter intentionem)" (Thomas Aquinas 1888-1906, 1948, IIa-IIae, q. 64, a. 7, responsum). The idea is that consequences that are "in the intention" of the agent are in some way wanted or willed by that agent and thus are inseparable from the moral act as such. On the other hand, consequences that are "beyond the intention" of the agent are entirely unwanted and are merely tolerated as inevitable. Thus, when in this paper we refer to a direct killing, we mean that the death of the victim is in the intention of the killer; that is, the death is somehow willed by that agent. It must be specified further that a direct killing can be either active or passive: one can commit direct killing just as easily by injecting poison into a patient (by commission) as by depriving him of beneficial food and water (by omission). Finally, if we characterize a human action by its object, circumstances, and end (Thomas Aquinas 1888-1906, Ia-IIae, q. 18 , aa. 2-4), we should specify that direct killing defines the object - what is immediately moving the will to action and specifies what kind of action it is-not the end (sometimes confusingly called "intention"). Moreover, if we determine that an action is a direct killing, no circumstance, however dire, can ever justify it.

Traditionally, the criteria used to discern whether there is a double effect are formulated as follows:

(1) The act in itself is good or indifferent;

(2) The agent intends the good effect and not the evil effect;

(3) The good effect is not produced by the evil effect; and

(4) There is a proportionately grave reason for causing the evil effect (Cavanaugh 2006, p. 26).

The first condition's purpose is to preclude actions known to be intrinsically evil, such as the direct killing of the innocent. More generally, one may never commit an action that is known from the outset to be morally evil, in order that a good may come about (Cavanaugh 2006, pp. 26-28). The second condition guarantees that the agent's intent (in intentione as defined above) is good as regards both his ends (what Aquinas calls the finis operantis) and the means (finis operis) he uses to obtain those ends. The agent may not, in other words, willfully or voluntarily want the evils that will result (Cavanaugh 2006, p. 27; Thomas Aquinas 1888-1906, IIa-IIae, q. 141, a. 6 ad 1). The third condition (which largely reiterates the first two conditions) is meant to emphasize the idea that "the end does not justify the means." In other words, a good end does not justify evil means that are in intentione. Although here the condition states simply that the "good effect" must not be "produced by the evil effect," we will follow Cavanaugh in interpreting it to mean "the good effect must not be willed as the means to obtain the evil end" (Cavanaugh 2006, pp. 29-31). Finally, the fourth condition considers the just proportion that must exist between the good sought and the evil consequences that are tolerated. Clearly, to tolerate evils, one must have a sufficiently grave reason to seek the good that will, unintentionally, bring those evils about. Delineating the exact threshold beyond which the evil consequences are disproportionate is tricky, but clearly, the evil consequences must not be enormously graver than the good sought (Cavanaugh 2006, pp. 31-32). Regarding our discussion, it would not be proper to consider tolerating a preventable death, if someone else's life or limb were not in grave danger.

When the conditions are applied to the scenario, it is easy to see that the first condition is fulfilled, since the actionintubating patient A to save his life-is a good. Regarding the second, no one has the intent, in any way, of depriving patients B, C, and D of life support; it is simply impossible to provide it to them. For the third, the good effect hoped for patient $\mathrm{A}$ is not in any meaningful sense done at the expense of any of the other patients. It cannot be said that the deaths of patients B, C, and D are a means to save patient A, since they are not causally linked at all: the death of some of the patients is inevitable, and the medical staff is simply trying to make the best of a bad situation. Finally, regarding the fourth condition, the obligation of medical personnel to save the lives they can save, as best they can, is grave enough that tolerating the deaths of patients $\mathrm{B}, \mathrm{C}$, and D is not disproportionate.

Thus, it is not difficult to argue that "depriving" patients $\mathrm{B}, \mathrm{C}$, and D of life support is not the intent of medical personnel in the least. Giving patients B, C, and D palliative care is not direct killing. Let us now examine a different scenario: the one that is really at issue in this paper.

Scenario 2: Again, we have four patients, $\mathrm{A}^{\prime}, \mathrm{B}^{\prime}, \mathrm{C}^{\prime}$, and $\mathrm{D}^{\prime}$, and everything is as before, except that, this time, patient $\mathrm{D}^{\prime}$ is already intubated and using a ventilator, and patients $\mathrm{A}^{\prime}, \mathrm{B}^{\prime}$, and $\mathrm{C}^{\prime}$ all arrive later. Patients $\mathrm{A}^{\prime}, \mathrm{B}^{\prime}$, and $\mathrm{C}^{\prime}$ have a greater possibility of recovering than patient $\mathrm{D}^{\prime}$. Nevertheless, patient $\mathrm{D}^{\prime}$ is still benefiting from his treatment-the 
treatment would not be considered futile or disproportionate for him. Would it be morally acceptable to withdraw life support from patient $\mathrm{D}^{\prime}$, and to transfer it to, say, patient $\mathrm{A}^{\prime}$ (who is the one with the greatest chance of survival and recovery)?

It is clear from the references above that Emanuel, Daly, and Truog, would support such a policy. The authors appear to approach the issue using reasoning that is fundamentally utilitarian: the maximization of benefits to the greatest number of patients. While there is nothing wrong in principle with attempting this, a natural law approach, as we have outlined in the first scenario, would urge us to be mindful of our already existing obligations to individual human beings. In short, we should be careful that in the effort to maximize the good, no evil is voluntarily intended (in the sense we have defined the term). We concur with Daly that.

the common good emerges in social situations in which each person is given access to the goods he or she needs to live a life befitting a human person. Put differently, the common good exists when a society respects and promotes the normative dignity of all of its members. The common good differs from utilitarianism insofar as the former emerges when a society promotes the good of its all members. In contrast, the latter directs agents to do the action that produces the greatest overall benefit for the individuals affected by the action. While utilitarianism permits certain people and groups to be "left out," the common good does not (Daly 2020).

Emanuel et al. justify their recommendation to reallocate ventilators and ICU from patients currently benefiting them to other patients with a greater prognosis according to the principle of maximizing benefits. They write that, "Because maximizing benefits is paramount in a pandemic, we believe that removing a patient from a ventilator or an ICU bed to provide it to others in need is also justifiable and that patients should be made aware of this possibility at admission" (Emanuel et al. 2020, p. 4). We agree that it is better to save someone likely to benefit from treatment than to lose two lives because one patient unlikely to benefit is depriving another of useful treatment. A consideration of the approaches most likely to maximize benefits is part of prudent stewardship of resources and care for the common good. Purposely minimizing benefits would be irresponsible. However, concern for the maximization of benefits should also include protection of the community's unwavering respect for individual dignity. The removal of proportionate care from a patient under treatment risks terminating his life and makes him an unwilling sacrificial victim. Such a practice is not beneficial to the community's commitment to the common good, in which each person has inviolable dignity.
For this reason, we retain the idea that certain actions are evil by their very nature - intrinsically evil—and thus can never be acceptable under any circumstance of time or place, and among these is, of course, the direct and intentional killing of the innocent (Cavanaugh 2006, p. 27). ${ }^{1}$ Although direct killing is off-limits, the question remains: does the withdrawal of life support in Scenario 2 constitute a direct killing? Or is it more like the patients' deaths in Scenario 1: death is foreseen, but merely tolerated, not intended?

Can the case be made for withdrawing life support from patient $\mathrm{D}^{\prime}$ and offering it instead to patient $\mathrm{A}^{\prime}$, or should such an action be regarded as an intentional killing of patient $\mathrm{D}^{\prime}$ ? It seems to us much more difficult in Scenario 2 to separate the deprivation of live-saving support (which, it bears repeating, is still beneficial to patient $\mathrm{D}^{\prime}$, independently of the other patients' needs) from the good object of attempting to save the life of patient $\mathrm{A}^{\prime}$. If so, then the death of patient $\mathrm{D}^{\prime}$ would be in the medical staff's intention (in intentione), and for this reason, such an action would be a kind of direct killing. Emanuel et al. recognize the emotional difficulty involved in applying their recommendation to reallocate to patients with a better prognosis. The authors note that the withdrawal "will be extremely psychologically traumatic for clinicians-and some clinicians might refuse to do so" (Emanuel et al. 2020, pp. 4-5). They do not make their recommendation lightly and insist that it does not demand the killing of patients. Our analysis, however, concludes that there are good philosophical grounds for the clinicians' resistance.

Proponents of the reallocation from patient $\mathrm{D}^{\prime}$ to patient $\mathrm{A}^{\prime}$ might argue that the finis operis of allocating scarce resources to the one most likely to benefit medically exists in both scenarios. The doctor could be said to choose the reallocation of resources and simply accept the unintended decline in the health of patient D' (Scenario 2), just as he accepts the unwilled health decline of patient $\mathrm{D}$, from whom treatment is withheld and never begun (Scenario 1). In both cases, the doctor is intending here and now the prudent distribution of limited resources. In both cases, he is constrained to administer those resources and thereby deprive some patients of them.

In order to resolve this question, it is useful to turn once again to double effect by looking at each of the criteria in turn.

As regards the first criterion, for the act of withdrawing care to be morally acceptable, we first need to demonstrate that it is not intrinsically immoral: in short, that

\footnotetext{
${ }^{1}$ We recognized that the existence of moral absolutes has been debated in Catholic circles for for decades. See for example (Curran 1975; Finnis 1991; Fuchs 1971; John Paul II 1993; May 1989). This question, however, is not only pertinent to Catholic natural law theory, but also to ethics in general. See Midgley (1993).
} 
it is not a kind of direct killing that is in intentione. While the ultimate goal-saving patient $\mathrm{A}^{\prime}$ - -has not changed and remains good, we contend that saving patient $\mathrm{A}^{\prime}$ is now intimately tied to disconnecting patient $\mathrm{D}^{\prime}$. Not only is the disconnecting of $\mathrm{D}^{\prime}$ now a necessary condition for connecting $\mathrm{A}^{\prime}$, but — crucially — the medical staff must deliberately and voluntarily set out to disconnect patient $\mathrm{D}^{\prime}$, while remaining free to refrain from doing so. Therefore, it seems difficult to argue that the disconnection (and hence the death) of $\mathrm{D}^{\prime}$ is not "in the intention" (in intentione) of the medical staff. It is something that they have, on some level, willed, even if reluctantly. Therefore, it is difficult to consider the disconnection of $\mathrm{D}^{\prime}$ a truly separate moral act from the intubation of $\mathrm{A}^{\prime}$. If evil is directly intended, if it is "in the intention" of the agent, then an intrinsically evil action-namely, direct killing-has occurred here.

To help discern if such is the case, it is helpful to examine the second condition of double effect. It is not apparent that the evil effect is entirely unwilled. In Scenario 1, medical staff do their best to save the patients they can and, try as they might, they are unable to save patients $\mathrm{B}, \mathrm{C}$, and $\mathrm{D}$; in Scenario 2, medical staff decide that they won't save patient $\mathrm{D}^{\prime}$ (by extubating), but will save patient $\mathrm{A}^{\prime}$.

Similarly, it also appears that there is a problem regarding the third condition, as the death of patient $\mathrm{D}^{\prime}$ is directly instrumental for saving the life of patient $\mathrm{A}^{\prime}$.

If the first three conditions were convincingly fulfilled, the fourth condition, regarding proportionality, would pose less of an issue: there is an emergency in our scenario, and people's lives are at stake. However, the first three conditions have not been met. Thus, the good achieved by saving patient $\mathrm{A}^{\prime}$ is not proportional to the objective injustice committed against patient $\mathrm{D}^{\prime}$.

\section{The ethics of withholding vs. withdrawing treatment}

Advocates for the reallocation of scarce medical resources from patient $\mathrm{D}^{\prime}$ to patient $\mathrm{A}^{\prime}$ in Scenario 2 might argue that the distinction between withholding and withdrawing is not per se morally determinative. They could appeal to the fact that many bioethicists would allow for the withdrawal of a ventilator if the deterioration of patient's condition rendered such treatment disproportionate or futile. They contend that the widely accepted moral permissibility of withholding treatment from patient $\mathrm{D}$ in Scenario 1 indicates that patient $\mathrm{D}^{\prime}$ could have the same treatment withdrawn in Scenario 2.

Sulmasy and Sugarman make a compelling case that a morally relevant distinction exists between withholding and withdrawing medical resources from patients (Sulmasy and Sugarman 1994). In their essay, the authors ask the reader to imagine two twins Prima and Secunda, who are suffering from cyanosis due to a simultaneous carbon monoxide poisoning that renders them urgently and vitally in need of oxygen. In other words, both their biological makeups and their afflictions are equivalent. Unfortunately, only one respirator with sufficient oxygen and tubing is available for the hapless twins. Since no objective clinical criteria can distinguish one twin from another as a more likely beneficiary of the treatment, the staff leaves the allocation to a coin flip. Prima happens to win, thus leaving Secunda without the help she needs. In such a tragedy, no one blames the doctors who treat Prima for Secunda's death because they withheld potentially beneficial medical treatment from her. However, once they have allocated the respirator to Prima, were the parents to request a reallocation to Secunda because she was generally better behaved than Prima, then the authors note that most would find Prima's withdrawal reprehensible. If the parents simply decided to flip the coin again after beginning Prima's treatment (without any consideration of the children's behavior), most onlookers would still be troubled if Prima were removed from needed care to accomodate Secunda's lucky second flip victory. The argument that Prima's care could be withdrawn since it could have been withheld had the coin fallen differently fails to appreciate the unique moral import of discontinuing proportionate care. The authors conclude that a real moral distinction does exist between withholding and withdrawing beneficial medical care to patients in otherwise similar situations. Sulmasy and Sugarman identify the existence of a patient's prima facie claim on the medical system to continue therapy so long as there is some likelihood of its success.

We will now further clarify the justification for Sulmasy and Sugarman's moral insight. Without such a clarification, an objector might concede that current treatment is a reasonable "tie-breaker" in favor of patient $\mathrm{D}^{\prime}$ if he has the same likelihood of medical benefit as patient A', but deny that the morally relevant presumption in favor of continuing treatment is sufficient to favor patient $\mathrm{D}^{\prime}$ in cases in which the patients do not enjoy an equal likelihood of benefit. Thus, the objector might argue that if patient $\mathrm{A}^{\prime}$ has a significantly superior likelihood of medical benefit, then this likelihood outweighs the claim of patient $\mathrm{D}^{\prime}$ to continue ventilation.

In response, we recall that a morally relevant doctorpatient relationship includes the doctor's responsibility to continue proportionate care with a reasonable likelihood of success. To end proportionate care willfully is to betray the doctor's duty for his patient's wellbeing. In Scenario 2, the doctor has established a bond of care with patient $\mathrm{D}^{\prime}$ that is not present with the other patients $\mathrm{A}^{\prime}, \mathrm{B}^{\prime}$, and $\mathrm{C}^{\prime}$. Moreover, the discontinuation of proportionate care (regardless of a patient's inferior likelihood of success when compared to other patients) constitutes the willful termination of life of the patient through the removal of critical care that is precisely sustaining the patient. The evil act of killing patient 
$\mathrm{D}^{\prime}$ becomes the chosen instrument of promoting the chances of survival for patient $\mathrm{A}^{\prime}$.

While it is tragically true that in times of crisis, patients in need cannot receive unlimited resources, such unfortunate circumstances do not justify willfully sacrificing one patient's life for the sake of another's. We cannot do evil to one patient to benefit another one in need. The violation of the dignity of one person for the sake of maximizing the good of the collective ends up damaging the community's appreciation for human dignity. As Sulmasy and Sugarman pithily conclude, "robbing Peter to pay Paul is different from paying Paul instead of Peter" (Sulmasy and Sugarman 1994, p. 221).

\section{Conclusion}

We disagree with those who advance the possibility of withdrawing life-saving medical interventions from patients who are still benefiting from them on the sole grounds that other patients might benefit more. We hold that those who are currently benefiting from advanced medical interventions should only interrupt their treatment if, in the judgment of medical personnel and, if at all possible, taking into account the wishes and needs of the patient and his family, the treatment is deemed futile, burdensome, or disproportionate. We also hold that it is morally acceptable for the patients themselves to opt for palliative care if they consider that being intubated and connected to a ventilator is burdensome or disproportionate. However, it is not acceptable to withdraw life-saving therapies from patients who both want them and would benefit from them: such a course of action would be a kind of direct killing. We agree, therefore, with Sulmasy and Sugarman, the NCBC, and the Anahuac University in their assessment that we must never withdraw critical care when the patient is evidently benefiting from the care, and without making a reasonable attempt to communicate with the patients or their surrogates.

\section{Compliance with ethical standards}

Conflict of interest None.

Research involving human participants and/or animals Not applicable.

Informed consent Not applicable.

\section{References}

Anahuac University Mexico. (2020). Ethical Criteria Guideline for Health Emergencies in Mexico in the Context of COVID-19 Pandemic. School of Bioethics. https://www.anahuac.mx/mexico/
EscuelasyFacultades/bioetica/sites/default/files/inline-files/Ethic al_Criteria_Guideline for_Health_Emergencies.pdf

Cadenas, J. F., \& Valdés, I. (2020, March 30). Health workers and unions at Madrid's Ifema field hospital: "It's a disaster". El País. https://english.elpais.com/society/2020-03-30/health-workersand-unions-at-madrids-ifema-field-hospital-its-a-disaster.html

Cavanaugh, T. A. (2006). Double-effect reasoning: Doing good and avoiding evil. Oxford University Press.

Centers for Disease Control and Prevention. (2020). Laboratory-confirmed COVID-19-associated hospitalizations. https://gis.cdc.gov/ grasp/covidnet/COVID19_3.html

Curran, C. E. (Ed.). (1975). Absolutes in moral theology? (revised edition). Greenwood Press.

Daly, D. J. (2020). Guidelines for rationing treatment during the COVID-19 crisis: A catholic approach. Health Progress, 101(2). https://www.chausa.org/publications/health-progress/article/ pandemic-coverage/guidelines-for-rationing-treatment-durin g-the-covid-19-crisis-a-catholic-approach

Di Camillo, J. (2020). Triage protocol guidelines. https://ncbcstore.org/ ncbc-resources-for-covid19/triage-protocol-guidelines

Emanuel, E. J., Persad, G., Upshur, R., Thome, B., Parker, M., Glickman, A., Zhang, C., Boyle, C., Smith, M., \& Phillips, J. P. (2020). Fair allocation of scarce medical resources in the time of Covid19. The New England Journal of Medicine. Advance online publication. https://doi.org/https://doi.org/10.1056/NEJMsb2005114

Feuer, A., \& McKinley, J. (2020, April 10). Virus deaths mount, but N.Y. Avoids predicted surge at hospitals so far. The New York Times. https://www.nytimes.com/2020/04/10/nyregion/new-yorkcoronavirus-hospitals.html

Finnis, J. (1991). Moral absolutes: Tradition, revision, and truth. Catholic University of America Press.

Fuchs, J. 1971. The absoluteness of moral terms. Gregorianum 52 (3): 415-458.

Horowitz, J. (2020, March 12). Italy's health care system groans under coronavirus-A warning to the World. The New York Times. https ://www.nytimes.com/2020/03/12/world/europe/12italy-coronaviru s-health-care.html

John Paul II. (1993). Veritatis splendor: The Splendor of Truth. St. Paul Books \& Media.

Lüdke, S. (2020, March 26). Madrid hospitals struggle to handle surge of corona patients. DER SPIEGEL. https://www.spiegel.de/inter national/europe/madrid-hospitals-struggle-to-handle-surge-ofcorona-patients-a-1a9ede1b-e62f-45f1-aa36-063f36c24240

May, W. E. (1989). Moral absolutes: Catholic tradition, current trends, and the truth (Vol. 1989). Marquette University Press.

McNeil, D. G. (2020, May 11). As states rush to reopen, scientists fear a coronavirus comeback. The New York Times. https://www. nytimes.com/2020/05/11/health/coronavirus-second-wave-infec tions.html

Midgley, M. 1993. Can’t we make moral judgements? Palgrave Macmillan US. https://doi.org/10.1007/978-1-137-09446-9.

NCBC Ethicists. (2020). Ethical concerns with COVID-19 triage protocols. National Catholic Bioethics Center. https://ncbcstore.org/s/ NCBC-Concerns-with-Triage-Protocols-Final.pdf

NYC Health. (2020). COVID-19: Data. https://www1.nyc.gov/site/doh/ covid/covid-19-data.page

Snell, R. J. (2020). The coronavirus pandemic and the ethics of triage. Culture of Life Foundation. https://cultureoflife.org/2020/03/26/ the-coronavirus-pandemic-and-the-ethics-of-triage/

Sulmasy, D., and J. Sugarman. 1994. Are withholding and withdrawing therapy always morally equivalent? Journal of Medical Ethics 20 (4): 218-222. https://doi.org/10.1136/jme.20.4.218.

Thomas Aquinas. (1888-1906). Summa theologiae. Leonina: IV-XII. Typographia polyglotta.

Thomas Aquinas. (1948). The summa theologica of St. Thomas Aquinas. Benzinger. 
Truog, R. D., Mitchell, C., \& Daley, G. Q. (2020). The Toughest Triage: Allocating Ventilators in a Pandemic. The New England Journal of Medicine. Advance online publication. https://doi.org/https ://doi.org/10.1056/NEJMp2005689

Vergano, M., Bertolini, G., Giannini, A., Gristina, G., Livigni, S., Mistraletti, G., \& Petrini, F. (2020). Clinical ethics recommendations for the allocation of intensive care treatments, in exceptional, resource-limited circumstances. http://www.siaarti.it/SiteA ssets/News/COVID19\%20-\%20documenti\%20SIAARTI/SIAAR TI\%20-\%20Covid-19\%20-\%20Clinical\%20Ethics\%20Reccomen dations.pdf

White, D. B., Katz, M., Luce, J., \& Lo, B. (2020). Allocation of scarce critical care resources during a public health emergency. https://
ccm.pitt.edu/sites/default/files/UnivPittsburgh_ModelHospitalRe sourcePolicy_2020_04_15.pdf

White, D. B., \& Lo, B. (2020). A Framework for Rationing Ventilators and Critical Care Beds During the COVID-19 Pandemic. JAMA, 1773-1774.

Publisher's Note Springer Nature remains neutral with regard to jurisdictional claims in published maps and institutional affiliations. 